REVISTA CRIOULA N ${ }^{\circ} 20-2^{\circ}$ SEMESTRE $/ 2017$

\title{
SAIR DO ANONIMATO: A IDENTIDADE SOCIAL DE MULHERES no romance de Paulina Chiziane
}

\section{Getting out of anonymity: the Social IDentity in a novel by Paulina Chiziane}

\author{
laná Souza Pereira ${ }^{1}$ \\ "A árvore que não dá fruto \\ É xingada de estéril. \\ Quem examinou o solo?"
}

(Bertold Brecht)

DOI: 10.11606/issn.1981-7169.crioula.2017.137707

RESUMO: Este artigo propõe-se a discutir a identidade social de mulheres no romance Ventos do apocalipse (1999), da moçambicana Paulina Chiziane. Nele, a mulher tem acesso à voz para contar uma experiência histórica de seu país: a guerra de desestabilização de Moçambique. Histórias de muIheres personagens e uma voz narrativa feminina se misturam para compor o enredo beligerante do livro. O fio condutor da narrativa é o ponto de vista daqueles que sofreram a guerra, não daqueles que a fizeram. Há, entretanto, na narrativa, o desejo de refletir e problematizar verdades e papéis sociais no universo da aldeia, num esforço contínuo para apreender a condição da mulher e sua multiplicidade e complexidade, procurando perceber a sua identidade social.

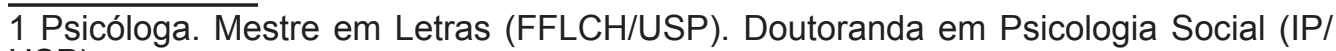
USP). 
ABSTRACT: This article proposes to discuss the social identity of women in the novel Ventos do apocalipse (1999), mozambican novel by Paulina Chiziane. In it, the woman has voice to tell a historical experience from her country: the war of mozambican destabilization. Stories of female characters and a female narrative voice mix to compose the book's belligerent plot. The thread that leads the narrative is the point of view of those who suffered the war, not from those who did it. There is, in the narrative, a desire to reflect and problematize truths from the social roles in the local village, as a continuous effort to apprehend the woman's condition and his multiplicity and complexity, seeking to perceive their social identity.

PALAVRAS-CHAVE: Ventos do apocalipse; Identidade social; Guerra; Moçambique.

KEYWORDS: Ventos do apocalipse; Social identity; War; Mozanbique.

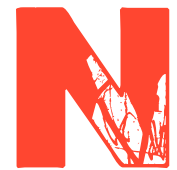

o cenário da literatura moçambicana, Paulina Chiziane é considerada a primeira mulher a escrever um romance, com a publicação de Balada de amor ao vento, em 1990. Ventos do apocalipse (1999) é o seu segundo romance; uma espécie de testemunho da autora sobre as atrocidades cometidas durante a guerra de desestabilização². Nele a escritora denuncia a violência desse conflito contra a população rural de seu país. O horror da guerra é representado em Ventos com a crueza que a denúncia exige, mas tam-

2 Segundo a historiografia recente de Moçambique, a expressão "guerra de desestabilização" se explica pelo emprego de forças externas a Moçambique (Rodésia, África do Sul e EUA apoiando os guerrilheiros da RENAMO, e URSS e Cuba, o governo da FRELIMO) e pelo método político, que visava impor mudanças na estrutura social, política e econômica do país. Esta guerra durou dezesseis ano. 
bém com a delicadeza de uma narradora ${ }^{3}$ apegada aos seus detalhes. Mulheres pululam em seu enredo, como personagens, diferente de Terra sonâmbula (1992), de Mia Couto, que trata do mesmo assunto.

Interessa, para a autora, mostrar a presença de mulheres nessa atmosfera sangrenta. Afinal, elas não apenas sofreram os efeitos dessa guerra, mas também lutaram com suas famílias contra ela. Tiveram que deixar suas casas e aldeias. Viram de perto a morte de filhos e maridos. Foram aprisionadas. Estupradas. Morreram:

Um choro moribundo ouve-se perto. Descobrem-no. É uma criança pequenina, três mesitos apenas e está presa nas costas de um cadáver. Recolhem-na assustados. Olham uma vez para o cadáver da mãe que tem o pavor bem estampado no rosto. As ervas em volta estão pintadas de sangue vivo, sofreram pisoteio, aqui houve luta [...] (CHIZIANE, 1999, p. 168).

Este é o cenário de horror da guerra do qual as mulheres fizeram parte. Em Ventos, elas integram o grupo de sobreviventes do ataque da aldeia de Mananga, no interior do país, tendo como questão central a sobrevivência coletiva. Os níveis narrativos do romance exploram a realidade histórica e social de Moçambique, ao lado da ficção, nas escolhas e falas das personagens, no enredo, na sua temática, nas imagens da guerra e nas próprias reflexões da narradora sobre o fenô-

$\overline{3}$ Na dissertação de mestrado, Vozes femininas de Moçambique (2012), utilizei a terminologia narradora defendendo a ideia de que a voz narrativa do romance era de uma mulher. Afirmei, portanto, que o romance apresentava uma narradora que contava a história, dada a maneira como esta história era contada no livro. 
meno da violência desmedida imposta ao aldeão comum. É, portanto, um romance indispensável para quem quer entender melhor a história recente de Moçambique.

Contudo, o presente trabalho pretende abordar a questão da identidade social de mulheres no romance de Paulina Chiziane. Buscando entender como as mulheres são caracterizadas na vida em aldeia, no grupo de refugiados e inseridas num contexto histórico. Para isso, dialogaremos com a linha da psicologia social contemporânea que entende identidade social como "aquilo que nos caracteriza como pessoa", dentro das condições sociais decorrentes da produção da vida material que determinam, em última análise, nossos papéis e nossa identidade social. Nos centraremos aqui na interpretação do psicólogo e professor Antonio da Costa Ciampa (1987), que concebe identidade como "um processar contínuo da definição de si mesmo", considerando-a, tanto em aspectos regulatórios como emancipatórios, de ações e discursos, tendo em vista as assimetrias de poder das relações sociais:

[...] cada indivíduo encarna as relações sociais, configurando uma identidade pessoal. Uma história de vida. Um projeto de vida. Uma vida-que-nem-sempre-é-vivida, no emaranhado das relações sociais. No seu conjunto, as identidades constituem a sociedade, ao mesmo tempo em que são constituídas, cada uma, por ela. A questão da identidade, assim, deve ser vista não como questão apenas científica, nem meramente acadêmica: é, sobretudo, uma questão social, uma questão política (CIAMPA, 1993, p. 127). 
Pensar a identidade social de mulheres envolve, portanto, uma discussão sobre a autonomia (ou não) e análises mais voltadas para tensões sociais vividas dentro do patriarcado. Envolve pensar a diferença sexual convertida em diferença política.

Pensemos, pois, nas mulheres representadas em Ventos do apocalipse. Elas são caracterizadas por sua participação no grupo de refugiados da guerra de desestabilização moçambicana, trazendo de suas aldeias referências que lhes dão um lugar e papel sociais no mundo, e, portanto, identificam-nas como sujeitos inseridos num contexto histórico. Cada uma delas constrói o seu "quem sou eu" no processo de interação com o outro e com o ambiente em que vivem. Isto estabelece um processo de construção de identidade em que se constatam semelhanças e dessemelhanças entre o "nós" e os "eles" - é nesse processo que acontecem não apenas as regulações das relações homem-mulher, mas também relações homem-homem e relações mulher-mulher. Vemos claramente o estado dessas relações em Ventos. As hierarquias e os privilégios ficam evidenciados pela narradora que gosta de ater-se aos detalhes.

É através dos detalhes que a narradora vai desvendando a identidade de mulheres articulada por elementos de igualdade, como o fato de serem aldeãs e integrarem o grupo de refugiados de guerra, e desigualdade, em função dos diferentes papéis sociais de homens e mulheres na aldeia, com distinção política entre os sexos.

$\mathrm{Na}$ vida social da aldeia de Mananga, temos relações patriarcais, mantidas pelos aldeões mesmo em tempos de 
guerra. Na fuga, o grupo é conduzido por um chefe que representa o poder masculino. Os homens tomam todas as decisões. As mulheres aparentemente obedecem. A narradora atenta-se para o fato de que, na aldeia, os destinos das mulheres são traçados pelas estruturas de comando/ patriarcal, é o "poder do macho" que impera. A forma de expressão do poderio/ político do grupo tem suas bases em estruturas, hierarquias e relações de dominação-exploração da mulher. Pela socialização, desde muito cedo, temos engendrados sentimentos que orientam os papéis sociais e as condutas de meninas e meninos:

Quando a noite chega, sentam-se à volta da lareira e contam histórias. Falam do futuro. A Sara diz que não quer ter nenhuma profissão, mas quer ser esposa e fazer filhos. O Mabebene diz que quando for grande quer ser presidente da república para acabar com todas as guerras do mundo. O mais pequeno, o Joãozinho, quer ter um camião para meter os produtos da machamba e vender no mercado da vila (CHIZIANE, 1999, p. 232).

A partir de uma rápida leitura da passagem acima podemos entender os limites traçados para as mulheres na aldeia: meninas podem sonhar apenas em se casar e ter filhos. Só a mulher sonha com o matrimônio e a maternidade. Meninos sonham com política e profissões.

$\mathrm{Na}$ fala de Sara, vemos os condicionamentos sociais traçados para a mulher na vida social da aldeia de Mananga e os limites das proibições circunscritos para sua atuação. 
Ventos conta muito das proibições e limitações impostas às mulheres moçambicanas pela tradição. Contesta e questiona o modelo de sociedade tradicional com os seus símbolos e representações de poder masculino. Propõe uma revisão de valores, das relações sociais e dos modos de ser de homens e de mulheres.

Para tanto, apresenta um final apocalíptico que vai contra a ideia de processo histórico como progresso linear. A destruição total, pela guerra, aponta para rupturas históricas que levam a pensar que o tempo perdido não está no passado de ruínas, mas no futuro a ser construído, no novo. Explodindo o continuum da história. Nesse sentido, o romance articula pensamento histórico e pensamento utópico. Apresenta tanto o ceticismo da crítica histórica sobre os meandros daquela guerra, quanto o movimento utópico de um vir-a-ser de sonhos, desejos e aspirações futuros para o país.

Nesse romance temos uma narradora que exerce a sua perplexidade diante da carnificina da guerra e coloca questões filosóficas sobre o ser humano, questionando o sentido daquelas vidas colocadas no limite:

Somos homens nobres, feitos à semelhança de Deus. É pouco provável. Se o homem é a imagem de Deus, então Deus é um refugiado de guerra, magro, e com o ventre farto de fome. Deus tem este nosso aspecto nojento, tem a cor negra da lama e não toma banho à semelhança de nós todos, condenados da terra [...] (CHIZIANE, 1999, p. 185). 
Nisso, os refugiados questionam a própria humanidade diante da angústia deflagrada pela guerra. Aproximam-se de Deus em seus aspectos mais repugnantes: na magreza, na sujeira e na fome. Como Condenados da terra, numa referência explícita a Frantz Fanon (2005). Os aldeões são também ex-colonizados e, num certo sentido, esse é um trecho que dialoga com o pensamento fanoniano de que o povo dominado está sempre se perguntando quem ele realmente é. Colocando sempre em questão o valor de suas vidas. No sentido de firmar a condição humana numa assimetria de poder em que um humano subjuga outro humano. Onde há dominação.

Avançando no romance, o leitor percebe que as mulheres aldeãs, muitas vezes, questionam os limites traçados para o sexo feminino na aldeia. Lutam por condições libertárias e igualitárias para elas, como parte de uma exigência maior, que se estenda para todos da aldeia. As tensões entre os sexos aparecem na vida em aldeia e na fuga da guerra. Diante da morte, os aldeões tornam-se mais iguais.

Como fugitivos da guerra também. É fugindo para a aldeia do Monte, pelo ataque sofrido na aldeia de Mananga, que as mulheres vão se identificando entre si, em seus papéis sociais, como mães, esposas e filhas, o que reforça suas identidades sociais femininas. Elas buscam compreender como se tornaram quem são e quem estão sendo no grupo de refugiados. Muitas delas passam por processos de auto-afirmação, o que envolve metamorfose. Elas ganham consciência de si - como sujeitos - o que, ao longo da narrativa, muda posicionamentos e atitudes. 
É notável, no romance, o desvelamento do pensamento das sociedades tradicionais moçambicanas que situam as mulheres muito abaixo dos homens, desde o seu nascimento. Uma voz narrativa onisciente cumpre o papel de dizer para o leitor quais são os comportamentos esperados de homens e de mulheres no grupo. Diz também das condições particulares de uma cultura que reforça o poder masculino e o papel feminino submisso. Ou seja, mulheres com identidades deterioradas pela socialização, decorrentes de um lugar subalterno fincado desde o momento em que as mulheres chegam ao mundo:

Ao nascer, a menina é anunciada com três salvas de tambor, o rapaz com cinco. O nascimento da menina é celebrado com uma galinha, o do rapaz celebra-se com uma vaca ou uma cabra. A cerimônia de nascimento do rapaz é feita dentro de casa ou debaixo da árvore de seus antepassados, a da menina é feita ao relento. Filho homem mama dois anos e mulher apenas um. Meninas pilando, cozinhando, rapazes estudando. O homem é quem casa, a mulher é casada. O homem dorme, a mulher é dormida. A mulher fica viúva, o homem só fica com menos uma esposa (CHIZIANE, 2004, p. 161).

O nascimento de uma mulher vale bem menos que o nascimento de um homem. Fica claro, para o leitor, os sentidos e significados da construção de identidades de homens e de mulheres nessa passagem. Salta aos seus olhos a inferioridade instituída para as mulheres desde o nascimento delas. 
Tem-se, assim, acesso, por meio da linguagem e dos sistemas simbólicos, aos privilégios dos homens e as discriminações sofridas pelas mulheres, pelo simples fato de serem do sexo feminino.

E é este também o princípio perverso do poder masculino. Homens possuem privilégios meramente por terem nascido homens. As mulheres partilham com eles o lugar e a cultura da aldeia, mas aquilo que identifica os aldeões, enquanto grupo, é produto de concepções masculinas que sustentam a exclusão das mulheres dos espaços de poder. Como um círculo que garante a manutenção e a permanência dessas relações de domínio. Os benefícios da masculinidade são herdados, nestes vínculos, pela tradição instituída:

Falamos dos tabus da menstruação que impedem a mulher de aproximar-se da vida pública de norte a sul. Dos tabus do ovo, que não pode ser comido por mulheres, para não terem filhos carecas e não se comportarem como galinhas poedeiras na hora do parto. Dos mitos que aproximam as meninas do trabalho doméstico e afastam os homens do pilão, do fogo e da cozinha para não apanharem doenças sexuais, como esterilidade e impotência. Dos hábitos alimentares que obrigam as mulheres a servir aos maridos os melhores nacos de carne, ficando para elas os ossos, as patas, as asas e o pescoço. Que culpam as mulheres de todos os infortúnios da natureza. Quando não chove, a culpa é delas, a culpa é delas (CHIZIANE, 1999, p. 35-36). 
Assim produz-se significados e valores, em um processo de produção e reprodução de "todo um modo de vida" de um povo. O interesse está, portanto, em veicular sentidos e significado para manutenção do patriarcado, criando maneiras de naturalização de suas forças sociais. Os homens, nessa cultura, formam uma espécie de casta privilegiada, a mulher é apenas uma pária. Os privilégios dos homens vão do berço ao túmulo. Ventos faz ver na cultura as interdições produzidas para as mulheres.

Apesar do romance incitar lampejos de consciência na nova geração de mulheres, que buscam uma nova posição de sujeito, no geral, temos no universo da aldeia herdeiras de uma tradição de submissão, confinadas na condição de vassalas. Aparecem alguns tipos subversivos, mas prevalecem as submissas. Desde o nascimento a identidade social da mulher é rebaixada e a narradora muitas vezes questiona a determinação dos papéis sociais das mulheres, refletindo qual espaço elas ocupariam no grupo. Reivindica um novo lugar de fala, em favor da própria expressão e da identidade feminina. Trava luta contra toda forma de naturalização da dominação-exploração das mulheres. Chama a atenção para as hierarquias entre os sexos e as ataca. Constituindo-se, assim, como uma narradora que partilha seus posicionamentos com o leitor e mostrando um engajamento em favor das mulheres. Usa, portanto, o espaço social da narração para disseminar ideias de igualdade entre os sexos, por isso sua narrativa tem uma dimensão utilitária (BENJAMIN, 1987).

Contudo, atentamos-nos para tais posicionamentos e engajamento como possibilidades de presença da autora do ro- 
mance na narrativa. Para melhor entender isso, dispomos da categoria autor implícito, de Wayne Booth (1980), que afirma que o romance registra diferentes versões do autor sobre si próprio, e que este detém o controle constante daquilo que é narrado. Nesta perspectiva, o autor está presente em todos os discursos de qualquer personagem a quem tenha sido conferido o emblema de credibilidade; seja de que modo for, o juízo do autor está sempre presente na sua obra, uma vez que, "embora o autor possa, em certa medida, escolher os seus disfarces, não pode nunca optar por desaparecer" (BOOTH, 1980, p. 35-38).

Entretanto, o leitor continua livre para interpretar a obra. Nada Ihe é imposto, apenas sugerido. Mantém-se, assim, a autonomia do autor, com a liberdade de escrever o que quiser, e também a do leitor, a quem nada é ensinado, apenas narrado. Nisso, o leitor é remetido para um campo ficcional que se afirma como realidade e que dialoga de perto com a realidade social e com os fatos históricos de Moçambique. Por uma perspectiva de quem durante muito tempo foi excluído.

Em Ventos, a personagem Minosse sintetiza a vida de mulher na condição de subserviência ao homem. Apresentando uma identidade social construída a partir da submissão da fêmea ao macho, sendo esta a base do processo de produção e reprodução de identidades para as mulheres da aldeia. Ela tem sempre os olhos baixos, voltados para os pés, curvando-se sempre para obedecer ao marido: "esposa dos velhos tempos, ainda preserva as tradições e o respeito dos antigos. Aproxima-se do marido, faz uma vênia, ajoelha-se solenemente, de olhos fitos no chão" (CHIZANE, 1999, p. 27). Pode- 
REVISTA CRIOULA N ${ }^{\circ} 20-2^{\circ}$ SEMESTRE/2017

mos dizer que a identidade social de Minosse se encaixa naquilo que Ciampa (1987) define como em "Uma vida-que-nem-sempre-é-vivida, no emaranhado das relações sociais". Ela sabe da liberdade e da autonomia que não possui. Quem nos esclarece isso é a narradora, ao comentar que a personagem faz o balanço da sua triste vida e pensa:

Vou morrer! Quando chegar ao céu hei-de encontrar Deus e haverá ajustes de contas. De certeza irá perguntar o que andei a fazer nesta vida errante. Ordenará aos seus ministros que Ihe mostrem a ficha da minha existência. E os ministros trarão esse lençol que dizem que há e que está escrito com letras de sangue. O que estará lá registrado? De certeza deve estar escrito assim: obedeceu, serviu e morreu. 0 que sempre desejei não está lá escrito porque os desejos da mulher não podem existir e nem são permitidos. [...] (CHIZIANE, 1999, p. 257).

O pensamento de Minosse resume vida e morte dos nascituros do sexo feminino na aldeia de Mananga. Cabe à mulher obedecer, servir e morrer. Nada mais. Assim, a narrativa expõe as interdições estabelecidas para as mulheres na cultura.

Já Wusheni, filha de Minosse, é uma personagem que evoca a transgressão. Antítese da mãe. Ela rompe com a tradição: recusa o marido imposto pelo pai, contrariando as regras do Lobolo4. Seu nome quer dizer aurora, como está no livro, que significa claridade, começo, primeiro tempo de um acontecimento. Portanto, nome e personalidade se encontram. Também podemos tirar daí toda uma simbologia da per-

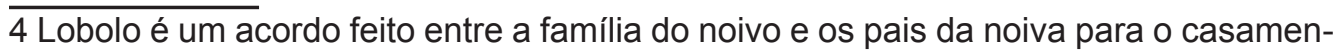
to, que envolve, entre outras coisas, presentes e um pagamento à família da noiva. 
sonagem para o despertar da consciência das mulheres. Ou o surgimento de um novo tempo para as mulheres na aldeia. Com o estabelecimento de novas relações sociais entre os sexos, graças aos muitos enfrentamentos da nova geração, Wusheni inscreve seu nome na posterioridade. Faz história.

No nível ideológico e no da ação do romance, podemos pensar a caracterização de Wusheni como possibilidade de ser um agente de mudanças em seu grupo social. No universo da sua aldeia, ela é uma personagem atuando para dizer que um outro modo de ser e estar no mundo é possível para as mulheres. Encenando lampejos da resistência feminina aos efeitos da dominação masculina ${ }^{5}$, que proíbe e desencoraja as condutas femininas tidas como impróprias. É uma personagem que diz "não" à postura submissa que se impõe às muIheres de sua aldeia, deixando claro que não quer ser a continuação da sujeição de sua mãe, Minosse. Dessa maneira, há uma personagem mostrando que a obediência das mulheres não deve ser transgeracional, ensinando que os ciclos podem e devem, enfim, ser rompidos.

De modo geral, em Ventos, a transgressão é usada como arma de interrupção da manutenção da subalternidade da mulher. O livro tem um discurso que inscreve as mulheres em seu centro, retirando-as do esquecimento e da invisibilidade por sua performance no texto, cabendo-lhes, pois, interpretar o mundo a sua volta, como parte da tarefa maior que é modificá-lo. A narrativa não apenas expõe a exclusão social

5 Entendemos dominação masculina nos termos de Pierre Bourdieu, que a define como um poder de homens sobre mulheres, que se manifesta nas relações sociais e ali também se dissimula, infiltrando-se invisível, camuflado ou inquestionado no pensamento e nas concepções de mundo. Trata-se de uma força que informa divisões sexuais arbitrárias e, para as mulheres, opressivas, capazes de aviltar, inibir ou impedir. 
das mulheres, mas também indica caminhos para superá-la quando desmistifica a impotência delas diante da tradição e da cultura. É uma narrativa revolucionária.

De certa maneira, a narrativa de Ventos do apocalipse aponta para a possibilidade de se pensar em novas identidades para as jovens mulheres moçambicanas. Evocando vivências de identidades sociais femininas ligadas estruturalmente ao rebaixamento do sexo feminino e questionando esse modelo. A narrativa contesta a ordem que estrutura tais identidades como inferiores em relação a dos homens, fazendo o esforço consciente de arrancar a naturalização da diferença sexual convertida em diferença política, no modo pelo qual vão se formando essas identidades. Senão, reconstruir, no que for possível, as identidades femininas.

Isto torna-se possível se entendermos a identidade social não como fixa ou imutável, mas como transitória, em diálogo constante com o contexto social e histórico em que emerge, podendo vir a ser modificada. Identidade é metamorfose, como nos diz Ciampa (1987). Nela, há sempre tempo de mudar... de ser diferente!

\section{REFERÊNCIAS BIBLIOGRÁFICAS}

BEAUVOIR, Simone. O segundo sexo, v. 2. 3. ed. Tradução de Sérgio Milliet. Rio de Janeiro: Nova Fronteira, 1990.

BENJAMIN, Walter. Magia e técnica, arte e política. São Paulo: Brasiliense, 1987. 
BOOTH, Wayne C. A retórica da ficção. Tradução de Maria Teresa H. Guerreiro. Lisboa: Arcaria, 1980.

BOURDIEU, Pierre. A dominação masculina. Tradução de Maria Helena Kuhner. Rio de Janeiro: Bertrand Brasil, 2010.

CIAMPA, Antonio da Costa. A estória do Severino e a história da Severina. São Paulo: Brasiliense, 1987.

CHIZIANE, Paulina. Ventos do apocalipse. Lisboa: Caminho, 1999.

FANON, Frantz. Os condenados da terra. Juiz de Fora: EDUFJF, 2005.

LANE, Silvia T. M., CODO, Wanderley (orgs). Psicologia social: o homem em movimento. São Paulo: Brasiliense, 2012.

Submissão: 04/09/2017

Aceite: 07/11/2017 